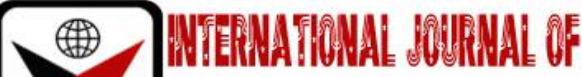

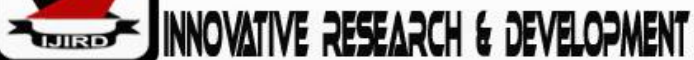

ISSN 2278 - 0211 (Online)

\section{The Spatial Distribution and Trends of Cases of Malaria Fever in Selected Areas of Mubi North Local Government Area, Adamawa State, Nigeria}

Jummai Vicent Zirra
Lecturer, Department of Geography, Adamawa State University Mubi, Nigeria
Samuel Hyellamada Jerry
Lecturer, Department of Geography, Adamawa State University Mubi, Nigeria
Danjuma Ijudigal Garandi
Lecturer, Department of Geography, Adamawa State University Mubi, Nigeria
Yahaya Rayyan Ibrahim
Student, Department of Geography, Adamawa State University Mubi, Nigeria

\begin{abstract}
:
The study on 'The Spatial Distribution and Trends of Cases of Malaria Fever in Selected Areas of Mubi North Local Government Area of Adamawa State' was conducted to assess the trends and spatial distribution of cases of malaria fever in some selected areas in Mubi north local government area which include; Digil, Lokuwa, Sabon-layi and Vimtim for the period of last five years (2014-2018). Where the study clearly shows that the trends of malaria in the selected areas of the Mubi north have been positively increasing yearly as from 2015-2018, with Lokuwa ward having the highest increase rate 589.3000 yearly among the selected areas and Vimtim ward having the lowest increase rate 18.00000 yearly among the selected areas. And also, the study clearly shows that cases of malaria fever in the selected areas of Mubi north is not evenly spatially distributed among the areas, with some areas experiencing high cases of malaria fever than other areas. Also the study went further to identify the causes and effects of malaria fever in the study areas and the possible way of tackling the trends, the study clearly shows that indiscriminate waste disposal in unauthorized places, provides breeding grounds for mosquitoes is the main cause of malaria fever in the study area, while others are land filling, poor environmental sanitation e.t.c which leads to the death of some few people in the area. Going with by results of findings of the study, almost all the populace have access to Long Lasting Insecticides Treated Nets (LLITN) which serves as a way of preventing the widespread of malaria cases. The objectives of this study were achieved through the use of both the primary and secondary data obtained from the sources. Some recommendations were made in other to tackle the trends of malaria cases, which include Government should encourage house to house weekly inspection in order to maintain proper hygiene conditions so as to reduce the increase level of malaria cases. Government should also employ the services of health educators so that they can educate the populace on what malaria is and its effect to human health.
\end{abstract}

Keywords: Malaria, LLITN, trends, fever and distribution

\section{Introduction}

Malaria is a major public health problems and cause of suffering and premature death in tropical and sub-tropical countries of the world (Robert et al, 2005). The preventable disease has reached endemic proportions in many countries of the world and continues to spread unchecked (WHO 2010). African children under five years and pregnant women are more at risk of malaria fever. Fatally afflicted children often die less than 72 hours after developing symptoms. For those children who survive, malaria drains vital nutrients from them impairing their physical and intellectual development, (WHO 2000). It is estimated that more than one million children living in Africa die daily from direct or indirect effects of malaria infection (Russels, 2004).

Malaria is a singled celled disease caused by single celled protozoan parasites of the genus plasmodium belonging to the apicomplexa phylum (Krief et al..2009). Malaria parasite (plasmodium species) are spread from one person to another through the bite of hematogenous female adults of mosquitoes belonging to the insect genus anopheles, these mosquitoes primarily inhabit the tropical and sub-tropical parts of the world (Robert et al 2005).

In Nigeria alone, 60 million people experience Malaria attack at least twice in a year, with no less than $80 \%$ of the population exposed to the disease (WHO, 2009). Scott et al. (2002) ascribed $90 \%$ of health problem caused by Malaria to environmental conditions. To corroborate this, Paul, (1997) emphasized the role of temperature on the range, development, timing and intensity of Malaria outbreak. He described mosquito as hot weather insects that have fixed 
thresholds for survival. For instance, Anopheles mosquito and falciparum malaria transmission are sustained only where the winter temperature is kept above $16^{\circ} \mathrm{C}$. In the northern part of the country (Nigeria) the transmission rate is approximately uniform throughout the year, in the north, there is a marked difference between the high transmission rate in the short-wet season, and low transmission rate in the long dry season (Lucas and Gills, 1998). Recent molecular studies have found evidences that malaria parasites probably jumped unto humans from the great apes, probably through infectious bite from mosquitoes (Kilama et al 2009).

In 2017, according to the commissioner for health, Dr. Fatima Atiku Abubakar, malaria accounted for $70 \%$ of over 850,000 cases of reported fever in Adamawa state. 'Malaria burden in the state as at 2017 is $70 \%$ (605,366 out of 856,086) reported cases of fever, where most of the affected people were women and children, leading to a seasonal malaria chemoprevention campaign targeting children in high risk locations like Mubi (north and south) and Michika is simply well-timed.

Malaria is one of the major causes of morbidity and mortality in the world with less than one million deaths annually as reported by W.H.O (WHO, 2010). Malaria is known to be endemic in the tropics at least most of today's human malaria population. Plasmodium falciparum, and plasmodium vivax may have had their origin in west Africa respectively (Joy et al 2003). Nigeria is known for a high prevalence of malaria and it is a leading cause of morbidity and mortality in the country (Federal Ministry of Health, 2001). Available records shows that at least 50\% of the population of Nigeria suffers from at least one episode of malaria each year and accounts for over $45 \%$ of all out-patients visit (Federal Ministry of Health) and responsible for an estimated annual reduction of $1.3 \%$ in economic growth for the countries with the highest burden, Nigeria inclusive, (Onwujekwe et al, 2000) therefore imposes a great burden on the country in terms of pain and trauma suffered by its victims as well as loss in outputs and cost of treatments (Onwujekwe et al, 2000).

The epidemiology of malaria over small areas remains poorly understood, and this is particularly true for malaria during epidemics in Northern part of Nigeria, where transmission intensity is low and is also characterized by acute illness within and varies between years. There have been epidemics of malaria affecting $73 \%$ of children under five years and $37 \%$ of Adults specifically pregnant women, causing deaths of mostly infected population in Mubi north. A common feature of malaria in Mubi north is that, there is always overall low potential disease risk in an average year.

Despite the availability of basic malaria control tools, it has not been clear why malaria has been on the increase. It is therefore important to establish the knowledge levels of the community on the causes of highland malaria and the available control strategies, with the aim of controlling and preventing future outbreaks.

Malaria is prone in some areas of Mubi north due to poor environmental management and lack of good knowledge on how to avoid mosquitoes in the area. The purpose of this research is to assess the trends and spatial distribution of cases of malaria fever within the study area, through getting information on causes and effects of malaria fever from questionnaires and information that will help in knowing the trends and spatial distribution of cases of malaria fever will be sourced from the various health care centers in the study area, which at the end of this research, the findings gotten will help to tackle malaria prone areas, areas most affected by malaria cases, and control measures to be taken in controlling malaria in the study area and also the inhabitants of the areas will be enlighten with knowledge on how to keep the environment clean and safe is in the line of these problems, the research aims to access the trends and spatial distribution of cases of malaria fever in selected areas of Mubi north Local Government Area, Adamawa state.

\subsection{Study Area}

Mubi North lies between latitude $9^{0} 26^{\prime} \mathrm{N}$ and $10^{\circ} 16^{\prime} \mathrm{N}$ and longitude $13^{0} 16^{\prime} \mathrm{E}$ and $13^{0} 44^{\prime} \mathrm{E}$. It is bounded by Michika LGA to the north, Mubi south LGA to the south, Cameroon to the east and by Hong LGA to the west according to Adamawa State Ministry of Lands and Survey (ASMLS, 2009).

\subsubsection{Climate}

Mubi has a tropical climate. In winter, there is much less rainfall than in summer. According to Köppen and Geiger, the climate is classified as tropical wet and dry (Aw). In Mubi, the average annual temperature is $25.4^{\circ} \mathrm{C}$, and about $935 \mathrm{~mm}$ of precipitation falls annually. The driest month is January, with $0 \mathrm{~mm}$ of rainfall, where most precipitation falls in August, with an average of $258 \mathrm{~mm}$. The warmest month of the year is April, with an average temperature of $29.3^{\circ} \mathrm{C}$. In August and December, the average temperature is $23.4^{\circ} \mathrm{C}$; it is the lowest average temperature of the whole year. The difference in precipitation between the driest month and the wettest month is $258 \mathrm{~mm}$. The average temperature varies during the year by $5.9^{\circ} \mathrm{C}$ (Adebayo, 2010). 


\section{Methodology}

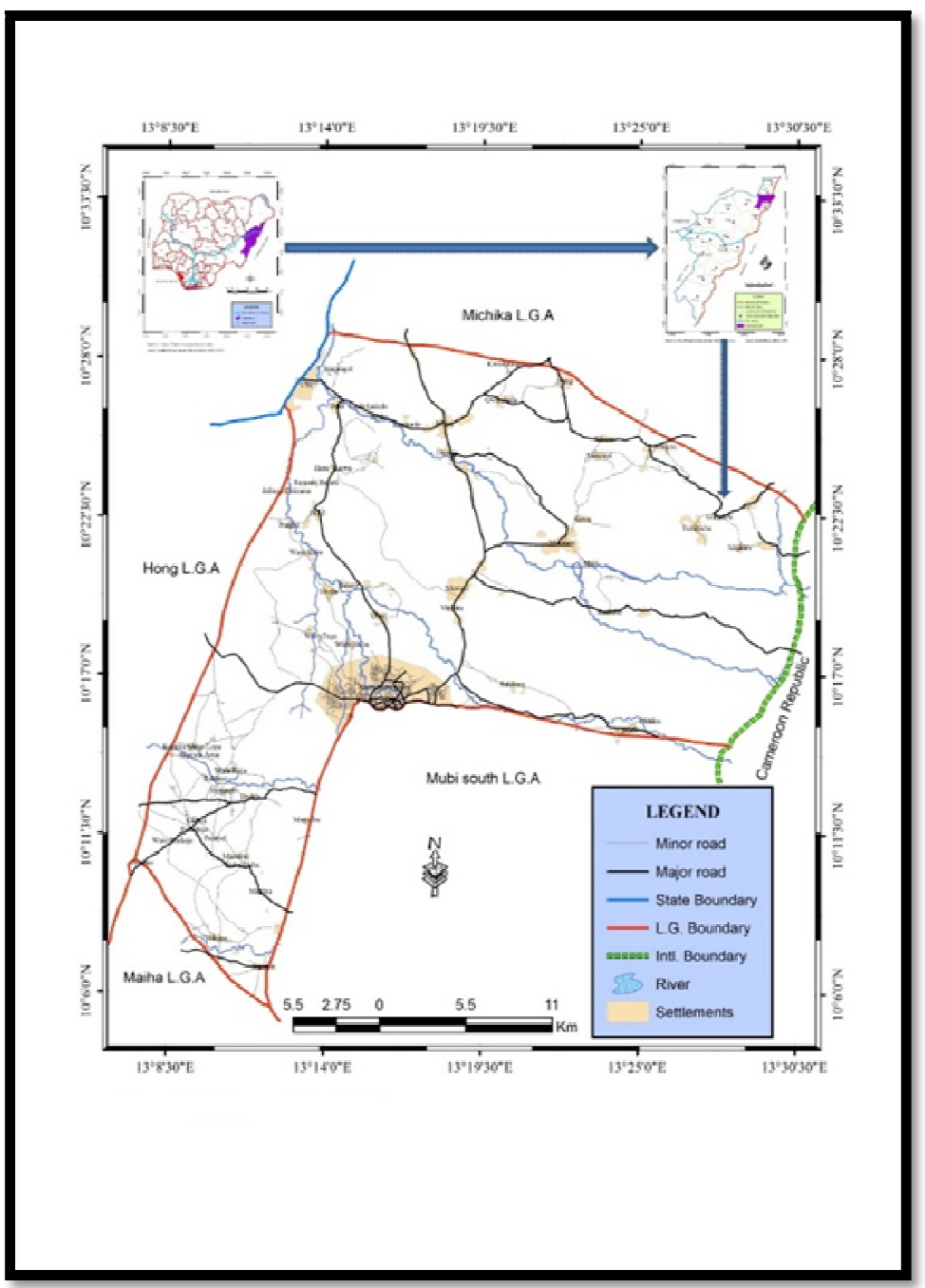

Figure 1: Map of Mobi North LGA

Source: Modified from Arcmap10.3.2020

\subsection{Introduction}

This section deliberates on the methods used in the collection of data and analysis, and the sources of the data.

\subsection{Sources and Types of Data}

The types of data used in this research are quantitative data and the materials required for this study was sourced from both the primary and the secondary data sources.

The primary data is the populace knowledge on the causes and effects of malaria fever in the study area which was obtained through physical observations, field work, questionnaires, and purposive discussion with some victims of malaria cases.

The secondary data are cases of malaria fever recorded in the various health care centers within the selected areas of the study area which was obtained from hospital, dispensary and clinic records, and the unpublished documents such as studies conducted on the related topics, reports of research works on the subject matter in relevant textbooks, journals, and seminar papers, etc.

\subsection{Sampling Technique}

The sample size requirement for questionnaire schedule will be determined using the Cochran's formula for calculating sample size for infinite population (Cochran 1977) which is expressed as.

$$
n_{o=\frac{Z^{2} P(1-P)}{e^{2}}}
$$

where: $\mathrm{n}_{0}=$ desired sample size $\mathrm{Z}=$ standard normal deviation set at 95\% confidence level (1.96)

$\mathrm{P}=$ percentage picking a choice or response $(0.5)$ and $\mathbf{e}^{2}=$ confidence interval $(0.05)$

This implies that for the four sites entire unknown population, the sample size for questionnaire to be administered will be.

$$
n_{o=\frac{(1.96)^{2}(0.5)(1-0.5)}{(0.05)^{2}}}=384.16
$$

Therefore, the total sample size will be 384 respondents. But due to financial factor, 200 questionnaires were administered across the selected areas in Mubi north local government area. 
Purposive sampling and simple random sampling were used in this research. Purposive sampling was used in the selection of sites which includes; Digil, Lokuwa, Sabon-layi and Vimtim. And simple random sampling was used in the selection of respondents. Questionnaires were administered randomly in the selected sample areas.

\subsection{Method of Data Collection}

Primary data were collected through physical observation, purposive discussion with some affected victims, which helped in identifying the causes and effects of malaria fever in the study areas. Where hospitals, dispensaries and clinic records helped in assessing the trends and spatial distribution of cases of malaria fever in the study areas.

\subsection{Method of Data Analysis}

Having obtained data from a primary source, which is the questionnaire, the data was analyzed with the use of quantitative statistical measures using statistical software known as IBM SPSS which presents the results in tables, graphs, and charts, for the analysis, proper presentation of the data was generated. This set of data was used to explain the first objective of the study which is identifying the causes and effects of malaria fever in the study area.

And for the secondary data source, which is the records of cases of malaria fever recorded in hospitals, clinics and dispensaries as of 2014 -2018 was compiled so as to know the trends and spatial distribution of the infectious disease (malaria) and also to know the area with the highest recorded cases. These results were used in explaining the second and third objective of the study.

\section{Results and Discussion}

Within the study area, were the results will be used in identifying the cause and effect of malaria fever. Two hundred (200) questionnaires were administered in the study area; one hundred and ninety-five (195) were retrieved. And also, the results obtained from the secondary data sources, which will be used in assessing the trends and spatial distribution of cases of malaria fever in the selected study areas.

\begin{tabular}{|c|c|c|c|c|}
\hline Knowledge & Digil & Lokuwa & Sabon-Layi & Vimtim \\
\hline Yes & $50(100 \%)$ & $49(98.0 \%)$ & $46(97.9 \%)$ & $47(97.9 \%)$ \\
\hline No & $0.0 \%$ & $1(2.0 \%)$ & $1(2.1 \%)$ & $1(2.1 \%)$ \\
\hline Total & $50(100 \%)$ & $50(100 \%)$ & $47(100 \%)$ & $48(100 \%)$ \\
\hline
\end{tabular}

Table 1: Knowledge of the Respondents

Source: field survey, 2020

The result in table 1:Indicates that majority of the respondents in the study area have the knowledge on malaria fever, with just little of those who don't.

\begin{tabular}{|c|c|c|c|c|}
\hline $\begin{array}{c}\text { Indiscriminate } \\
\text { waste disposal }\end{array}$ & Digil & Lokuwa & Sabon-layi & Vimtim \\
\hline Yes & $38(76.0 \%)$ & $45(90.0 \%)$ & $36(76.6 \%)$ & $44(91.7 \%)$ \\
\hline No & $12(24.0 \%)$ & $5(10.0 \%)$ & $11(23.4 \%)$ & $4(8.3 \%)$ \\
\hline Total & $50(100.0 \%)$ & $50(100.0 \%)$ & $47(100.0 \%)$ & $48(100.0 \%)$ \\
\hline
\end{tabular}

Table 2: Indiscriminate Waste Disposal as a Major Cause of Malaria

Source: Field Survey, 2020

The result from table 2 shows that majority of the respondents in the study area revealed that indiscriminate waste disposal in their various areas can contribute to the spread of malaria fever within the area, which serve as breeding ground for mosquitoes.

\begin{tabular}{|c|c|c|c|c|}
\hline Method & Digil & Lokuwa & Sabon-layi & Vimtim \\
\hline $\begin{array}{c}\text { Dumping of waste in } \\
\text { unauthorized places }\end{array}$ & $28(56.0 \%)$ & $26(52.0 \%)$ & $28(59.6 \%)$ & $31(64.6 \%)$ \\
\hline Burning & $15(30.0 \%)$ & $14(28.0 \%)$ & $11(23.4 \%)$ & $6(12.5 \%)$ \\
\hline Land filling & $7(14.0 \%)$ & $6(12.0 \%)$ & $2(4.3 \%)$ & $11(22.9 \%)$ \\
\hline Incinerators & $0(0 \%)$ & $4(8.0 \%)$ & $2(4.3 \%)$ & $0(0 \%)$ \\
\hline Others & $0(0 \%)$ & $0(0 \%)$ & $4(8.5 \%)$ & $0(0 \%)$ \\
\hline Total & $50(100 \%)$ & $50(100 \%)$ & $47(100 \%)$ & $48(100 \%)$ \\
\hline
\end{tabular}

Table 3: Method of Waste Disposal

Source: Field Survey, 2020

The results in table 3 indicates that the common method of waste disposal practiced within the study areas is dumping of waste in unauthorized places, which in turn will have a high impact in the spread of malaria fever in the areas. 


\begin{tabular}{|c|c|c|c|c|}
\hline Mortality & Digil & Lokuwa & Sabon-layi & Vimtim \\
\hline Yes & $14(28.0 \%)$ & $7(14.0 \%)$ & $8(17.0 \%)$ & $4(8.3 \%)$ \\
\hline No & $36(72.0 \%)$ & $43(86.0 \%)$ & $39(83.0 \%)$ & $44(91.7 \%)$ \\
\hline Total & $50(100.0 \%)$ & $50(100.0 \%)$ & $47(100.0 \%)$ & $48(100.0 \%)$ \\
\hline
\end{tabular}

Table 4: Cases of Mortality

Source: Field Survey, 2020

The result from table 4 presents the respondents experience on mortality cases as a result of malaria fever. With the results above, it shows that most of the respondents have not registered any case of mortality as a result of malaria fever among their families, with just few who registered.

\begin{tabular}{|c|c|c|c|c|}
\hline Number of mortalities & Digil & Lokuwa & Sabon-layi & Vimtim \\
\hline None & $36(72.0 \%)$ & $38(76.0 \%)$ & $39(83.0 \%)$ & $44(91.7 \%)$ \\
\hline 1 & $9(18.0 \%)$ & $2(4.0 \%)$ & $6(12.8 \%)$ & $4(8.3 \%)$ \\
\hline 2 & $2(4.0 \%)$ & $6(12.0 \%)$ & $1(2.1 \%)$ & $0(0.0 \%)$ \\
\hline$\geq 3$ & $3(6.0 \%)$ & $4(8.0 \%)$ & $1(2.1 \%)$ & $0(0.0 \%)$ \\
\hline Total & $50(100 \%)$ & $50(100 \%)$ & $47(100 \%)$ & $48(100 \%)$ \\
\hline
\end{tabular}

Table 5: Number of Mortalities

Source: Field Survey, 2020

The table 5 above presents the analysis of mortality records in families. Most of the respondents have recorded no cases of mortality in their families, with just little proportion that have recorded, were some recorded 1 , some 2 , while others 3 .

\begin{tabular}{|c|c|c|c|c|}
\hline Prevention & Digil & Lokuwa & Sabon-layi & Vimtim \\
\hline Mosquito nets & $39(78.0 \%)$ & $29(58.0 \%)$ & $37(78.7 \%)$ & $39(81.2 \%)$ \\
\hline Mosquito coils and flitting & $5(10.0 \%)$ & $16(32.0 \%)$ & $10(21.3 \%)$ & $7(14.6 \%)$ \\
\hline Anti-malaria drugs & $5(10.0 \%)$ & $4(8.0 \%)$ & $0(0.0 \%)$ & $2(4.2 \%)$ \\
\hline None & $1(2.0 \%)$ & $1(2.0 \%)$ & $0(0.0 \%)$ & $0(0.0 \%)$ \\
\hline Total & $50(100 \%)$ & $50(100 \%)$ & $47(100 \%)$ & $48(100 \%)$ \\
\hline
\end{tabular}

Table 6: Method of Prevention

Source: Field Survey, 2020

The response from the respondents in the study area on the various methods used in controlling malaria infection is displayed in the table 6 above, whereby the use of mosquito nets carries a large proportion within the study area and this is because the government have tried their possible best in sharing of Long Lasting Insecticide Treated Nets (LLITN) among the populace. According to the results obtained only few uses mosquito coils and flitting and Anti-malaria drugs in preventing malaria infection.

\begin{tabular}{|c|c|c|c|c|}
\hline Personal hygiene & Digil & Lokuwa & Sabon-layi & Vimtim \\
\hline Refuse disposal & $21(42.0 \%)$ & $22(44.0 \%)$ & $20(42.6 \%)$ & $21(43.8 \%)$ \\
\hline Sewage disposal & $3(6.0 \%)$ & $7(14.0 \%)$ & $12(25.5 \%)$ & $12(25.0 \%)$ \\
\hline $\begin{array}{c}\text { Discharge of stagnant water } \\
\text { Clearing of surrounding } \\
\text { bushes }\end{array}$ & $10(20.0 \%)$ & $7(14.0 \%)$ & $5(10.6 \%)$ & $7(14.6 \%)$ \\
\hline Others & $16(32.0 \%)$ & $14(28.0 \%)$ & $10(21.3 \%)$ & $8(16.7 \%)$ \\
\hline Total & $0(0.0 \%)$ & $0(0.0 \%)$ & $0(0.0 \%)$ & $0(0.0 \%)$ \\
\hline
\end{tabular}

Table 7: Personal Hygiene Practiced by the Respondents

Source: Field Survey, 2020

The result from table 7 shows the most common personal hygiene practiced by the respondents in the study area in other to tackle the spread of malaria fever. Were refuse disposal seems to be the most common personal hygiene practiced by the populace, followed by clearing of surrounding bushes, followed by sewage disposal and then lastly discharge of stagnant water.

\section{Spatial Distribution of Malaria Cases in the Study Area}

In assess the spatial distribution of cases of malaria fever in selected areas of the study area were the results obtained from the various health care centers indicates that cases of malaria fever in the selected areas of Mubi north local government area is not evenly spatially distributed and this is due to some factors which include: human activities that provides breeding grounds for mosquitoes such as indiscriminate waste disposal in unauthorized places and also the climate of an area also determines the distribution of cases of malaria fever in the area. 
To show how cases of malaria fever in the study area is spatially distributed, a map was prepared by the researcher, were the distribution of malaria cases on the map were categorized into three: areas with high cases (Lokuwa), areas with moderate cases (Digil and Sabon-layi) and lastly areas with low cases (Vimtim).

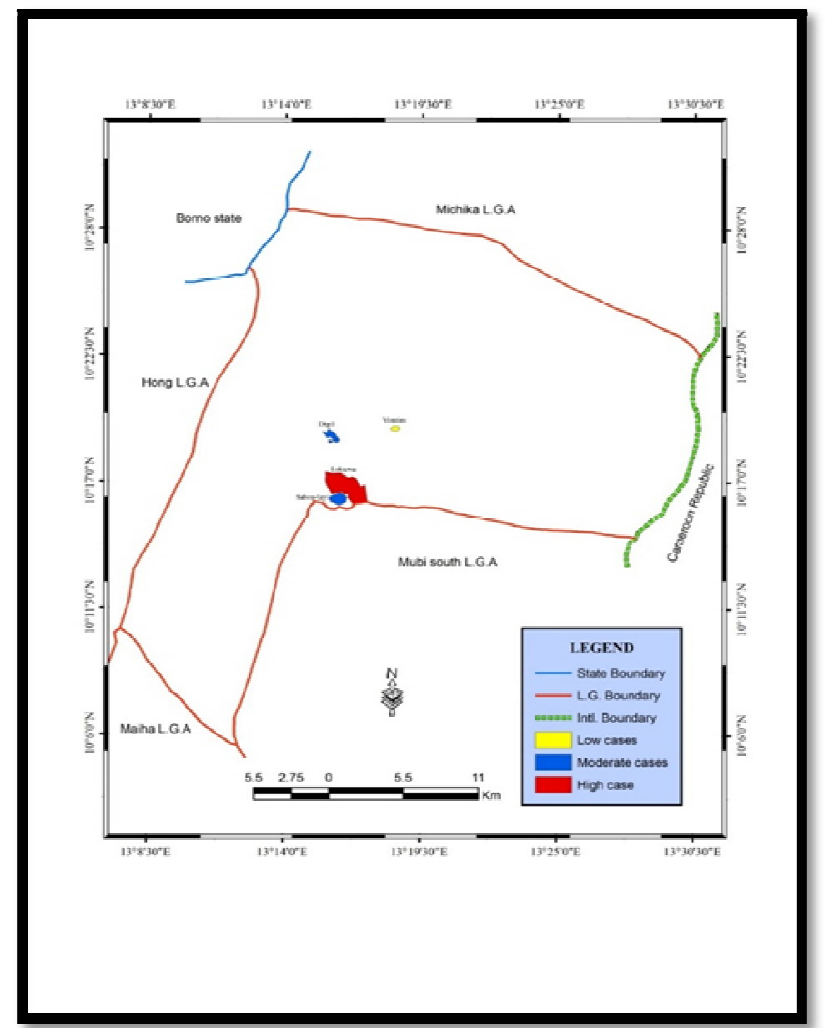

Figure 2: Map of Mobi North LGA showing Spatial Distribution of Cases of Malaria Fever in the Selected Study Area Source: Field Survey, 2020

4.1. Trends of Malaria cases in Digil, Lokuwa, Sabon-Layi and Vimtim wards of Mubi

\begin{tabular}{|c|c|c|c|c|}
\hline Year & Digil & Lokuwa & Sabon-layi & Vimtim \\
\hline 2014 & 1113 & 1511 & 966 & 874 \\
\hline 2015 & 1205 & 1342 & 880 & 783 \\
\hline 2016 & 1224 & 1794 & 984 & 751 \\
\hline 2017 & 1235 & 3021 & 1091 & 923 \\
\hline 2018 & 1394 & 3618 & 1164 & 894 \\
\hline \multicolumn{5}{|c|}{ Table 8: Annual Cases of Malaria Per Wards } \\
Source: Field Work, 2020
\end{tabular}

The above table 8 shows the annual cases (2014-2018) of malaria recorded in the selected areas of the study area. This data is sourced from the various health care centers found in the study area, which will be used in assessing the trends of cases of malaria fever in the selected areas of Mubi north local government area, which is the second objective of this study.

\begin{tabular}{|c|c|c|c|c|c|}
\hline & & & & & \\
Wards & & Coefficient & Std. Error & T-statistics & Probability \\
\hline Digil & C & 1056.600 & 47.43431 & 22.27503 & 0.0002 \\
& Time & 59.20000 & 14.30198 & 4.139287 & 0.0256 \\
\hline Lokuwa & $\mathrm{C}$ & 489.3000 & 457.7190 & 1.068996 & 0.3634 \\
& Time & 589.3000 & 138.0075 & 4.270059 & 0.0236 \\
\hline Sabon- & $\mathrm{C}$ & 834.9000 & 68.23736 & 12.23523 & 0.0012 \\
Layi & Time & 60.70000 & 20.57434 & 2.950277 & 0.0600 \\
\hline Vimtim & $\mathrm{C}$ & 791.0000 & 82.95099 & 9.535751 & 0.0024 \\
& Time & 18.00000 & 25.01066 & 0.719693 & 0.5237 \\
\hline
\end{tabular}

Table 9: Trends Equation

Source: Authors computation using E-view 8.0, 2020 
Table 9 shows the trend analysis of cases of malaria fever in the study area, which were obtained from trend equations. Malaria cases recorded in each ward were regressed against time. The coefficient of time from each ward will tell whether there is a positive trend or negative trend of malaria cases in the study areas. The coefficient of time also indicates the average increase/decrease in malaria cases per ward. (2014-2018).

In Digil ward, the intercept shows an average of 1056.600 Malaria cases in a year, which is the constant value from the table. However, the slope parameter of time indicates that malaria cases increase by an average of 59.20000 cases in Digil Ward annually. In Lokuwa ward, the intercept shows an average of 489.3000 cases of Malaria annually. However, the slope parameter of time being 589.3000 suggests that averagely, malaria cases increase by 589.3000 cases annually over the period of study 2014 -2018.while in Sabon-layi ward, the intercept shows an average of 834.9000 cases of Malaria annually. However, the slope parameter of time being 60.70000 suggests that averagely, malaria cases increase by 60.70000 cases annually over the period of study 2014 -2018. Similarly, in Vimtim ward, 791.0000 cases of Malaria were found to be the intercept as suggested by trend analysis result. The slope parameter of time suggests that 18.00000 cases of Malaria are added to already existing cases every year,

This implying that all the selected study areas have positive trend of Malaria cases within the period of study 2014-2018.

With Lokuwa ward with the highest increase rate of malaria cases per year (589.3000) is due to some factors which include; presence of slump areas, lack of good environmental sanitation and also the ward being located at the heart of the town, will involve several human activities which may create a favorable habitat for mosquitoes to breed and Vimtim ward with the lowest increase rate of malaria cases per year (18.00000) is due to rise and fall of malaria cases within the years (2014-2018). And also, the relief in which Vimtim is located can also have impact on malaria cases.

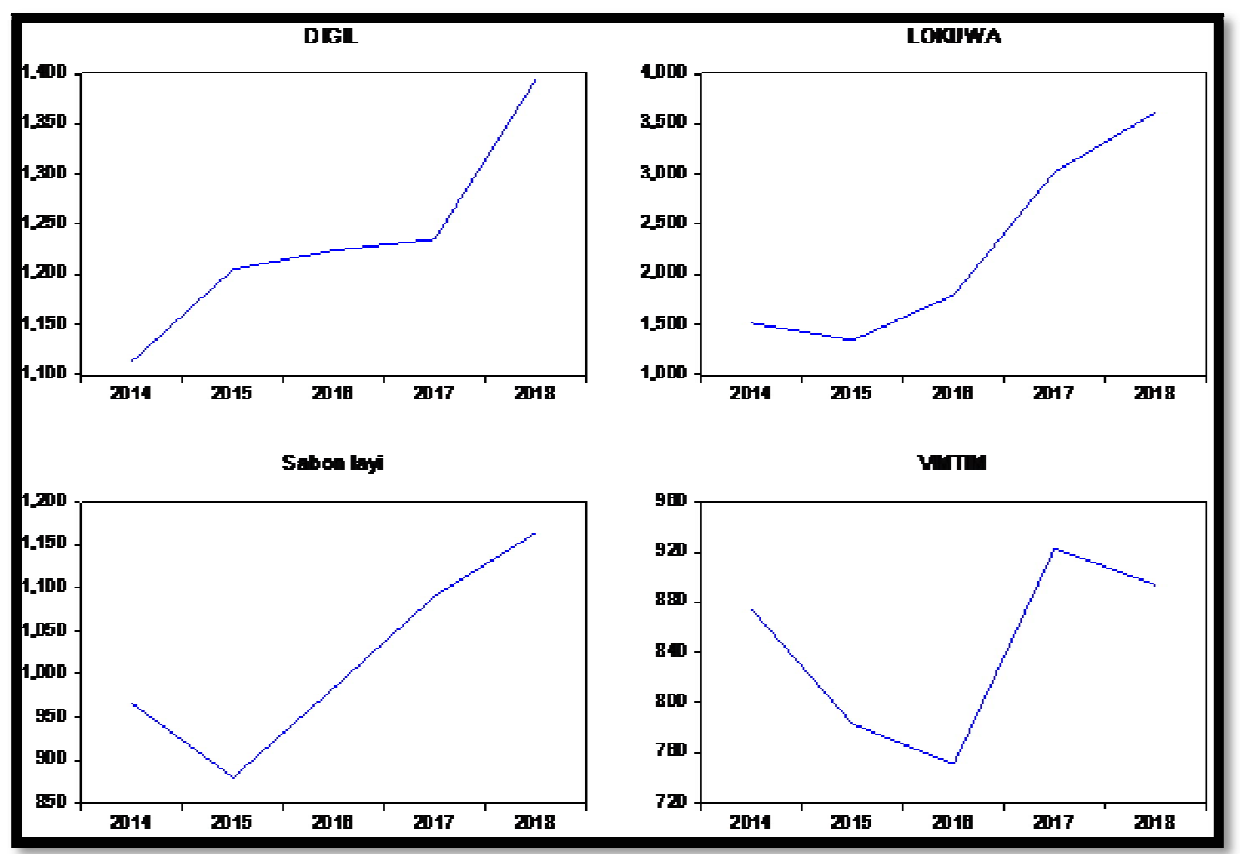

Figure 3: Graphical Trends of Malaria Cases in Digil, Lokuwa, Sabon-Layi and Vimtim Wards of Mubi for the Period 2014-2018

Source: Authors Computation Using E-View 8.0, 2020

According to the graphs, cases of malaria have been increasing positively from 2015-2018 in all the wards (Digil, Lokuwa and Sabon-layi) except in Vimtim where there was a decrease in the cases from 2015-2016 and a rapid increase from 2016-2017 and finally a little decrease from 2017-2018.

With the information presented in the graphs above, the statement made by the commissioner for health Dr. Fatima Atiku Abubakar in 2017 that 'malaria has accounted for 70\% of over 850,000 cases of reported fever in Adamawa state. Malaria burden in the state as at 2017 is $70 \%(605,366$ out of 856,086) reported cases of fever, where most of the affected people were women and children, leading to a seasonal malaria chemoprevention campaign targeting children in high risk locations like Mubi (north and south) and Michika is simply well-timed' have been proven.

\begin{tabular}{|c|c|c|c|c|}
\hline Wards & Mean & Median & Maximum & Minimum \\
\hline Digil & 1234.200 & 1224.000 & 1394.000 & 1113.000 \\
\hline Lokuwa & 2257.200 & 1794.000 & 3618.000 & 1342.000 \\
\hline Sabon-layi & 1017.000 & 984.0000 & 1164.000 & 880.0000 \\
\hline Vimtim & 845.0000 & 874.0000 & 923.0000 & 751.0000 \\
\hline
\end{tabular}

Table 10: Descriptive Statistics of the Variables

Source: Authors Computation Using Eview 8.0, 2020 
Table 10 above shows the mean, median, maximum and the minimum values of each ward of the study area, within the five years (2014-2018) were;

MEAN: it is a value that is gotten when all the cases of malaria fever recorded yearly within the 5 years (20142018) per each ward are summed up and divided by the number of years (5).

MEDIAN: the median value is obtained when all the cases of malaria fever recorded yearly within the 5 years (2014-2018) per ward are arranged in either ascending or descending order. The variable at the middle is said to be the median value. MAXIMUM: the maximum is the highest cases of malaria fever recorded in a ward within the five years (2014-2018). MINIMUM: the minimum is the lowest cases of malaria fever recorded in a ward within the five years (2014-2018).

\section{References}

i. Adebayo, A.A, (2010). Climate: Resources and Resistance to Agriculture. Eight Inaugural Lecture of Federal University of Technology, Yola.

ii. Cochran, W.G. (1977). Sampling technique (3rd edition). John Wiley and Sons. New York:

iii. Kilama, W, Ntoumi F and Lander F, (2009) malaria research agenda for the eradication era lancet 347(9700)1480.2.

iv. Krief J. Adolf S. Alain P. U (2009) the negligence on the killer disease malaria and it's menace in the nearest future (2 suppl): 118-127. (pubMed).

v. Onwujekwe O. E China R. I Okwonkwo P. O (2000): Economic burden of malaria illness a study of five malaria hyper endemic communities' health policy 2000, 54:149-159

vi. Robert U. Spencer G. N and Gloyd S. (2005). Malaria and other shocks in urban sub-Sahara Africa Acta Trop. 2012(3): 184-195.

vii. Russel S. 2004: The economic burden of illness for household in developing countries: A review is studies focusing on Malaria, tuberculosis and HIV/AIDS. American Journals of tropical medicine and hygiene, 71 (suppl2): 147-155.

viii. Scott, C. R. (2002). Attaining Global Health: challenges and Opportunities. Population Bulletin. Vol. 55, No. 1: Pp 25-28.

ix. WHO World health organization (2010) the outrageous implication of malaria infection and its consequences. Advert press Pp34-35.

x. World Health Organization (2008). World Malaria Report (WMR). WHO, Geneva, Switzerland.

xi. World Health Organization. (2009). 'Methods for surveillance of anti-malarial drug efficacy', World Health Organization, Switzerland. 